\title{
Essential oils against Candida spp: in vitro antifungal activity of Origanum vulgare
}

\author{
Marlete Brum Cleff ${ }^{1 \star,}$ Isabel Madrid ${ }^{2}$, Ana Raquel Meinerz ${ }^{2}$, Mário Carlos Araújo Meireles ${ }^{2}$, \\ João Roberto Braga de Mello', Maria Regina Rodrigues ${ }^{3}$ \\ and Jesús Jaime Hernández Escareño ${ }^{4}$
}

${ }^{1}$ Department of Pharmacology, Faculty of Veterinary, UFRGS-Federal University of Rio Grande do Sul - Porto Alegre, RS, Brazil.

${ }^{2}$ Department of Preventive Veterinary, Faculty of Veterinary, Federal University of Pelotas - Campus Universitário, $s / n^{\circ}$. Caixa Postal 354, CEP 96010-900, Pelotas, RS, Brazil.

${ }^{3}$ Department of Organic Chemistry, Chemistry Institute, Federal University of Pelotas, Campus Universitário, $\mathrm{s} / \mathrm{n}^{\circ}$ - Caixa Postal 354, CEP 96010-900, Pelotas, RS, Brazil.

${ }^{4}$ Universidad Autónoma de Nuevo León. UANL. Facultad de Medicina Veterinaria y Zootecnia, Av. Universidad S/N, Ciudad Universitaria. San Nicolás de los Garza, Nuevo León. C.P. 66451 México.

Accepted 8 February, 2013

\begin{abstract}
Experiments were conducted to evaluate the in vitro antifungal activity and determine chemical composition of Origanum vulgare essential oils. Nine Candida albicans (five clinical animal isolates and four ATCC strains), and three non-albicans species were studied; broth microdilution technique (CLSI) was used. Eight samples of commercial $O$. vulgare were submitted to hydrodistillation (Clevenger), and essential oils obtained were analyzed by gas chromatograph. Values of minimum inhibitory concentration (MIC) ranged from 1.0 to $0.065 \%$, the average of $\mathrm{MIC}_{50}$ was $0.62 \mu \mathrm{L} / \mathrm{mL}$ while the average of $\mathrm{MIC}_{90}$ was $5.52 \mu \mathrm{L} / \mathrm{mL}$ and essential oils EO1 and EO8 were the ones with the best results. Results of thymol/carvacrol ratio were, for essential oils (EO) (EO1, 10.20/12.67; EO2, 7.88/0.50; EO3, 6.18/0.71; EO4, 0.58/21.58; EO5, 20.62/1.34; EO6, 21.95/4.71; EO7, 16.68/0.77; EO8, 8.42/9.44), demonstrated that differences between concentrations of thymol and carvacrol influenced MIC. These results indicate that the 0 . vulgare essential oils evaluated in this study presented growth inhibition activity over Candida spp.
\end{abstract}

Key words: Origanum vulgare, Candida spp., essential oil, thymol, carvacrol.

\section{INTRODUCTION}

Knowledge about medicinal plants was for a long time the only therapeutic resource of many communities and ethnic groups. The use of plants as treatment to cure illnesses has been since early times (Simões et al., 2003). Still today in poorer areas of the country and even in big Brazilian cities, medicinal plants are comercialized in popular markets and found in backyards of residences (Simões et al., 2003; Sartoratto et al., 2004). Regarding antimicrobial activity, plants of Lamiaceae family have been of interest due to their potential (Arango et al., 2004; Giordani et al., 2004; Rehder et al., 2004). Many species of this family, introduced in Brazil, are medicinal plants; they produce essential oils and are also used as seasoning or as ornamental flowers. Among them, Origanum vulgare stands out (Arcila-Lozano et al., 2004; Rehder et al., 2004; Rodrigues et al., 2004; Cleff et al., 
2008a). Most important representatives of essential oils of this plant are terpenes, and among them monoterpenes and sesquiterpenes (Lambert et al., 2001; ArcilaLozano et al., 2004; Rehder et al., 2004; Rodrigues et al., 2004; Cleff et al., 2008b). Studies with purpose of determining activity of $O$. vulgare essential oils have shown and demonstrated bacterial and fungal activity against different pathogens and this is attributed to the content of carvacrol and thymol that are major compounds in some oils (Lambert et al., 2001; Arango et al., 2004; Arcila-Lozano et al., 2004; Chami et al., 2004; Nostro et al., 2004; Rehder et al., 2004; Busatta et al., 2007, 2008; Cleff et al., 2008b).

Nowadays, due to higher frequency of patients susceptible to fungal infections, a larger number of reports of isolates resistant to antifungal have been observed as well as a higher rate of therapeutic failure, mainly in candidiasis (Chami et al., 2004; Santos Jr. et al., 2005; Magill et al., 2006). This mycosis has frequently been associated with hospital infections in immunesuppressed subjects, and in veterinary practice their importance is growing due to several reports of illness in animals (Mueller et al., 2002; Moretti et al., 2004; Magill et al., 2006; Cleff et al., 2007, 2008a).

The aim of this study was to evaluate in vitro antifungal activity and determine chemical composition of eight samples of $O$. vulgare essential oils, mainly in relation to thymol/carvacrol rate.

\section{MATERIALS AND METHODS}

\section{O. vulgare samples}

Commercial oregano samples with botanical certification were acquired in the market. Eight samples of oregano of Chilean and Uruguayan origin were evaluated considering the molar thymol/ carvacrol rate. Samples were numbered and named as: 1, Erechim; 2, Aves; 3, El Moncayo; 4, La Rosa; 5, Del Gaúcho; 6, Goes; 7, Treichel; 8, Torrenueva.

\section{Isolation of essential oils}

Oregano samples were subjected to hydrodistillation for $4 \mathrm{~h}$ using a modified Clevenger type apparatus, according to the Brazilian Pharmacopeia IV (1988). After extraction, oils were dried in anhydrous sodium sulphate, filtered, and concentrated under ultrapure $\mathrm{N}_{2}$ and stored in amber flasks at $4{ }^{\circ} \mathrm{C}$. Essential oils obtained were named as EO1 (Erechim); EO2 (Aves); EO3 (El Moncayo); EO4 (La Rosa); EO5 (Del Gaúcho); EO6 (Góes); EO7 (Treichel) and EO8 (Torrenueva). The edium yield of essential oil (EO) in raw material was $1.282 \mathrm{~mL}$ ( $\mathrm{mL} E O / 100 \mathrm{~g}$ of oregano).

\section{Chemicals}

All chemicals (hexane, dichloromethane) were of analytical grade. Analytical standards such as $\alpha$-pinene, $\beta$-pinene, myrcene, $\alpha$ terpinene, p-cymene, camphene, limonene, 1.8-cineole, $\gamma$-terpinene, terpinolene, linalool, 4-terpineol, $\alpha$-terpineol, thymol and carvacrol were supplied by Sigma. RPMI Media 1640 (Gibco BRL,
Grand Island, NY, USA), Tween 80 (Sigma), Sabouraud dextrose agar (Oxoid, Basingstoke, UK), McFarland standard (bioMérieux, Marcy l'Etoile, France), and buffer 3-morpholinopropanesulfonic acid (MOPS) and phosphate-buffered saline (PBS) (Sigma) were also used in this research.

\section{Chromatographic analyses}

Essential oils were analyzed by gas chromatography with flame ionization detector (GC/FID - Schimadzu 17A) to identify main compounds. Chromatographic analyses were carried out in a chromatograph equipped with a DB-5 silica capillary column (methyl siloxane with $5 \%$ phenyl groups - $30 \mathrm{~m} \times 0.25 \mathrm{~mm} \phi$, film thickness $0.25 \mu \mathrm{m})$. Nitrogen was used as a carrier gas with a flow rate of 1.0 $\mathrm{mL} \mathrm{min}^{-1}$ and split ratio of 1:50. Injector and detector temperatures were both set at $280^{\circ} \mathrm{C}$. Column temperature was programmed to $40^{\circ} \mathrm{C}$, gradually increased to $145^{\circ} \mathrm{C}$ at $2^{\circ} \mathrm{C} \min ^{-1}$ and then increased to $280^{\circ} \mathrm{C}$ at $10^{\circ} \mathrm{C} \mathrm{min}{ }^{-1}$, which was held for $10 \mathrm{~min}$. Solution of each essential oil $\left(5.000 \mu \mathrm{g} \mathrm{mL}^{-1}\right)$ and chromatographic standards $(40 \mu \mathrm{g}$ $\mathrm{mL}^{-1}$ ) were prepared and $1 \mu \mathrm{L}$ was injected at the same conditions. The compounds in the oregano samples were identified by comparison with retention time of standards and literature data (Rodrigues et al., 2004).

\section{Candida spp. isolates}

Twelve (12) isolates were used for in vitro tests: nine $C$. albicans (five of mucous membrane and cutaneous tegument of dogs and four standard strains - ATCC 44858, 4053, 18804 and IOC 3691), and three were non-albicans species: $C$. parapsilosis (ATCC 22019), C. Iusitanie (ATCC 34449) and C. krusei (ATCC 34135). Regarding Candida spp. isolates, four isolates of $C$. albicans were from vaginal mucous membrane of canine and one isolate of cutaneous candidiasis was from a dog, from Pelotas, Rio Grande do Sul, Brazil. Isolated yeasts were maintained in subcultures in Sabouraud dextrose agar (SDA) and stored at $5^{\circ} \mathrm{C}$, in Mycology Laboratory, Veterinary College, UFPel; Standard strains were kindly supplied by Osvaldo Cruz Foundation (Fiocruz, INCQS), Rio de Janeiro, Brazil.

\section{Inoculums preparation}

Yeast inoculum was prepared by growing Candida isolates on SDA for $24 \mathrm{~h}$ at $35^{\circ} \mathrm{C}$ and then suspended in $5 \mathrm{~mL}$ of sterile physiological saline solution and homogenized. The inoculum suspension had its turbidity adjusted according to $0.5 \mathrm{McF}$ arland standards which corresponds to an initial inoculum with approximately $5 \times 10^{6} \mathrm{CFU}$ $\mathrm{mL}^{-1}$. Then, 1:50 dilution in sterile physiological saline solution was prepared, and another 1:20 dilution in RPMI Media 1640 was prepared in 96-well microtiter plate (Becton Dickinson Labware, Franklin Lakes, NJ, USA). Adjusted inoculum suspension $(100 \mu \mathrm{L})$ was dispensed in each well, resulting in desired final drug

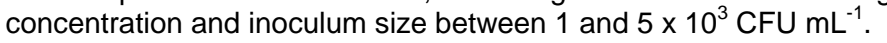

\section{Antifungal activity}

Microdilution in broth technique was used to evaluate susceptibility of Candida spp. against oils, according to National Committee for Clinical Laboratory Standards, NCCLS, M 27-A2 (CLSI) with few modifications. A $1 \%$ solution of Tween 80 as dispersant of essential oil in RPMI Media was used, avoiding micellas formation and favoring dilution. Ten (10) serial dilutions from stock solutions of essential oil of Origanum were prepared in RPMI medium with L- 
glutamine without bicarbonate and buffered with MOPS at $\mathrm{pH}$ 7.0. For yeasts, minimum inhibitory concentrations (MICs) were determined by subculturing $100 \mu \mathrm{L}$ of those concentrations from each well (1 to 10) of microtiter plate. Positive control (inoculum/ media) and negative control (essential oil/media) were placed into wells 11 and 12 . Plates were incubated aerobically at $35^{\circ} \mathrm{C}$ for $48 \mathrm{~h}$ with shaking. Susceptibility was expressed as MIC, defined as lowest concentration required to delay growth of fungi by $24 \mathrm{~h}$ of incubation in relation to the positive control. Also, minimum concentration were determined in $\mu \mathrm{g} / \mathrm{ml}$, capable to inhibit 50 and $90 \%$ from isolated, calculated as $\mathrm{MIC}_{50}$ and $\mathrm{MIC}_{90}$.

\section{RESULTS}

\section{Chromatographic analyses}

Table 1 shows the results obtained from chromatographic analysis of eight $O$. vulgare essential oils where the difference between phenol constituent can be observed. Analyzed oils presented the following concentrations regarding thymol/carvacrol rate: EO1, 10.20/12.67; EO2, 7.88/0.50; EO3, 6.18/0.71; EO4, 0.58/21.58; EO5, 20.62/1.34; EO6, 21.95/4.71; EO7, 16.68/0.77; EO8, 8.42/9.44. In Table 1, other important compounds such as 4 -terpineol, $\alpha$-terpinene, $p$-cymene, $\gamma$-terpinene and $\alpha$ terpineol can be observed. Figure 1 presents a graph with concentration variations (\%) of p-cymene, 4-terpineol, thymol and carvacrol, in different essential oil samples of $O$. vulgare (origanum), where it was possible to observe great variation in tymol/carvacrol rate.

\section{Antifungal activity}

After incubation period, the microdilution plates were observed, by the technique of microdilution in broth, to detect the sensitivity of isolates of Candida spp. to $O$. vulgare essential oils. Table 2 shows the results of the MIC of eight $O$. vulgare essential oils using this technique. In this table, the MIC did not demonstrate significant variation among different isolates; what is observed when pure antifungal substances are used. $\mathrm{MIC}_{50}$ and $\mathrm{MIC}_{90}$ are indicative of a less concentration capable of growth inhibition of 50 and $90 \%$ of the isolates. This data is shown in Table 3 , with an average of $\mathrm{MIC}_{50}$ of $0.62 \mu \mathrm{L} / \mathrm{mL}$ and the average of $\mathrm{MIC}_{90}$ of 5.52 $\mu \mathrm{L} / \mathrm{mL}$.

Results demonstrate susceptibility differences among field isolates, standards and different species of Candida. It was observed that the most active essential oils were one and eight (EO1 and EO8) which presented lower $\mathrm{MIC}_{90}$ values than other oils (EO2, EO3, EO4, EO5, EO6 and EO7).

\section{DISCUSSION}

Researchers have reported antimicrobial potentiality of essential oils, using different techniques of antifungigram as agar diffusion, disc diffusion testing and broth micro- dilution susceptibility assay, where the last used give good results (Lambert et al., 2001; Arango et al., 2004; Rehder et al., 2004; Busatta et al., 2007, 2008; Cleff et al., 2010).

These data are in accordance to what has been described in literature, where $O$. vulgare essential oil presents a great variation in composition, mainly in active compounds, where monoterpene phenols such as thymol and carvacrol reached 80.2 to $98 \%$ of total composition of this oil (Simões et al., 2003; Arcila-Lozano et al., 2004; Rehder et al., 2004; Rodrigues et al., 2004; Cleff et al., 2008). Geographic factors such as altitude, soil, climate, harvest, culture, drying process and storage conditions among others, have influence on composition, quality and amount of each compound present in essential oil from plants (Cox et al., 2000; Simões et al., 2003; Arango et al., 2004; Arcila-Lozano et al., 2004).

The higher values of $\mathrm{MIC}_{90}$ presented by six other essential oils (EO2 the EO7) can be justified by the variation in thymol/carvacrol compound rates (EO215.76; EO3-8.70; EO4-0.03; EO5-15.39; EO6-4.66 and EO2-21.66), showing always higher concentration of one in relation to the other.

Chromatographic analyses of oregano essential oil samples (EO1 and EO8) showed better result in vitro $\left(\mathrm{MIC}_{90}=3,54\right.$ and 3,87, respectively); presented mostly 4terpineol, thymol and carvacrol components who deserves attention to concentration balance between thymol (10.20 and 8.42) and carvacrol (12.67 and 9.44) associated to a large concentration of 4-terpineol (21.32 and 47.95), respectively. It was reported that the composition 4-terpineol acts be inducing deformations in the cell membrane, modifying consequently its permeability (Cox et al., 2000). Another factor to be considered is that the use of commercial oregano could have leaf mixtures, flowers and stems of $O$. vulgare in the sample, as well as the presence of different oregano genus in the same sample. Although all organs of a plant can accumulate volatile oils, its composition can change according to part or species studied, since just Origanum genus presents 39 different species (Simões et al., 2003).

Compounds without aromatic ring and/or hydroxyl groups, such as $\gamma$ - terpinene, $\alpha$-terpinene and $p$-cymene, monoterpenes hydrocarbons, were found in significant amount in those samples. That could justify the MIC values achieved by these essential oils (Nostro et al., 2004). Presence of the $p$-cymene, has an antagonistic effect with carvacrol and thymol, which would explain lower antimicrobial activity of essential oils EO2 (20.38); EO4 (13.96) and EO6 (7.01).

High concentrations of these compounds and their proportion are of great importance for effectiveness of the product. However studies have demonstrated that these isolated compounds do not have same efficiency of essential oil. Bio-synthetic precursors $\gamma$-terpinene and $p$ cymene, as well as $\alpha$-terpineol, 1.8-cineol and linalool, also showed antimicrobial activity, justifying higher efficiency 
Table 1. Concentration (\%) of compound in eight samples of $O$. vulgare essential oils analyzed by gas chromatography (GC/FID).

\begin{tabular}{|c|c|c|c|c|c|c|c|c|c|}
\hline $\mathrm{S} / \mathrm{N}$ & Compound ${ }^{\star *}$ & E01 & $\mathrm{EO2}$ & EO3 & $\mathrm{EO} 4$ & EO5 & EO6 & EO7 & EO8 \\
\hline 1 & $\alpha$-thujene & 0.63 & 2.15 & 0.71 & 0.63 & 0.90 & 0.12 & 0.31 & 0.25 \\
\hline 2 & $\alpha$-pinene ${ }^{\star \star *}$ & 53 & 0.51 & Id & 10 & nd & nd & $\mathrm{Nd}$ & nd \\
\hline 3 & Sabinene & 53 & 5.47 & 0.93 & 60 & 1.24 & 0.18 & 0.47 & 0.33 \\
\hline 4 & $\beta$-pinene ${ }^{\star \star}$ & 0.19 & 0.27 & nd & 13 & nd & nd & $\mathrm{Nd}$ & nd \\
\hline 5 & Myrcene ${ }^{\star \star \star}$ & 1.22 & 1.71 & 0.12 & 0.70 & 0.28 & 0.20 & 0.30 & 0.18 \\
\hline 6 & $\alpha$-phellandren & 1.47 & 2.27 & 3.54 & 1.80 & 2.28 & 1.73 & 2.26 & 2.47 \\
\hline 7 & $\alpha$-terpinene ${ }^{\star \star *}$ & 3.46 & 7.00 & 4.64 & 4.27 & 5.60 & 2.43 & 2.83 & 2.83 \\
\hline 8 & p-cim & 15.90 & 20.38 & 1.85 & 13.96 & 1.84 & 1.13 & 7.01 & 0.71 \\
\hline 9 & Limor & .04 & 6.22 & 4.92 & 3.65 & 3.74 & 2.59 & 3.44 & 3.60 \\
\hline 10 & 1,8-ci & 75 & 0.09 & nd & 0.17 & 0.07 & nd & 0.07 & 0.53 \\
\hline 11 & cis/tr & 0.56 & 0.62 & 0.04 & 0.43 & 0.26 & 0.13 & 0.24 & 0.08 \\
\hline 12 & $\gamma$-terpinene ${ }^{\star \star \star}$ & 3.69 & 8.31 & 4.25 & 4.10 & 7.80 & 5.91 & 2.18 & 4.86 \\
\hline 13 & ne hidrate & 0.11 & 0.97 & 0.34 & 0.27 & 0.27 & nd & 0.13 & 0.07 \\
\hline 14 & Terpinolene $^{\star * *}$ & 1.61 & 3.41 & 1.89 & 2.10 & 2.78 & 1.63 & 1.29 & 1.69 \\
\hline 15 & cis-sabinene hidrate & 0.26 & 2.36 & 0.54 & 0.55 & 0.61 & nd & 0.26 & 0.08 \\
\hline 16 & Linalool*** & 3.78 & 1.40 & 3.08 & 1.70 & 3.53 & 2.07 & 4.58 & 2.89 \\
\hline 17 & trans- $p$-men & 0.17 & 0.28 & 0.33 & 0.26 & 0.14 & 0.10 & 0.25 & 0.12 \\
\hline 18 & cis- $p$ & 0.16 & 0.09 & nd & 0.10 & nd & nd & $\mathrm{Nd}$ & 0.05 \\
\hline 19 & Born & 40 & 0.23 & 0.13 & 0.10 & 0.26 & 0.36 & 0.34 & 0.27 \\
\hline 20 & 4-terpi & 21.32 & 11.92 & 50.87 & 27.67 & 31.04 & 41.17 & 39.45 & 47.95 \\
\hline 21 & $\alpha$-terpi & 4.23 & 2.78 & 8.87 & 3.69 & 4.78 & 4.98 & 5.74 & 7.57 \\
\hline 22 & trans & 0.15 & 0.10 & 0.30 & 0.26 & 0.08 & 0.17 & 0.11 & 0.35 \\
\hline 23 & cis-piperitol & 0.10 & 0.06 & nd & 0.09 & nd & nd & 0.05 & nd \\
\hline 24 & Methyl thymol e & 1.00 & 1.41 & 0.30 & nd & 1.03 & 0.58 & 1.73 & 0.10 \\
\hline 25 & Methyl carvacrol eter & 1.92 & 2.60 & 0.57 & 5.78 & 2.41 & 3.04 & 2.80 & 0.71 \\
\hline 26 & Linalil acetate & 0.31 & 0.21 & nd & 0.42 & nd & nd & 0.26 & nd \\
\hline 27 & Gerani & 1.35 & 5.30 & 0.68 & 0.29 & 2.21 & 0.51 & 1.25 & 0.70 \\
\hline 28 & Thymol*** & 10.20 & 7.88 & 6.18 & 0.58 & 20.62 & 21.95 & 16.68 & 8.42 \\
\hline 29 & Carvacrol $^{\star \star *}$ & 12.67 & 0.50 & 0.71 & 21.58 & 1.34 & 4.71 & 0.77 & 9.44 \\
\hline 30 & Geran & 0.35 & 0.08 & 0.20 & nd & 0.51 & 0.21 & 0.47 & 0.20 \\
\hline 31 & $\beta$-caryophyllene & 0.98 & 1.12 & 2.60 & 1.04 & 3.10 & 3.22 & 2.34 & 2.92 \\
\hline 32 & Germacrene & 0.23 & 0.05 & nd & 0.64 & nd & nd & 0.07 & nd \\
\hline 33 & Spathulenol & 1.13 & 1.25 & 1.18 & 0.78 & 1.06 & 0.81 & 1.83 & 0.59 \\
\hline 34 & Caryophylene oxide & 0.60 & 0.98 & 0.23 & 0.56 & 0.24 & 0.07 & 0.51 & 0.05 \\
\hline
\end{tabular}

EO1, Erechim; EO2, Aves; EO3, El Moncayo; EO4, La Rosa; EO5, Del Gaúcho; EO 6, Goes; EO7, Treichel; EO8, Terranueva. ${ }^{\star \star} \mathrm{C}(\%)=$ normalised peak areas without using correction factors; ${ }^{* * *}$ compounds identified by comparasion with standards $; \mathrm{nd}=$ not detected. Other compounds were identified by literature data (Rodrigues et al., 2004; Busatta et al., 2008).

of essential oil when compared to isolated compounds (Simões et al., 2003). Action mechanism of essential oils is complex and it is not totally elucidated. Some studies suggested an alteration in activity of calcium canals, causing increase in permeability and liberation of vital intracellular constituents, promoting a decrease in intracellular ATP in cells. Simultaneously, it causes an increase in extracellular ATP, leading to rup-ture in cellular membrane of microorganism (Sikkema et al., 1994, 1995; Sartoratto et al., 2004). Antimicrobial activity can be due to damage caused to several enzymes, including those involved in production of energy and synthesis of structural components of microorganism (Lambert et al., 2001).

In the present work, samples analyzed, besides phenol compounds, 4-terpineol was sometimes in larger amount than thymol or carvacrol (phenolics compounds) and $\alpha$ terpineol; both terpenes alcohol, monoterpenes with hydroxyl group $(\mathrm{OH})$, were able to make polar hydrogen bonds, which justify the good result of $\mathrm{MIC}_{90}$. For 


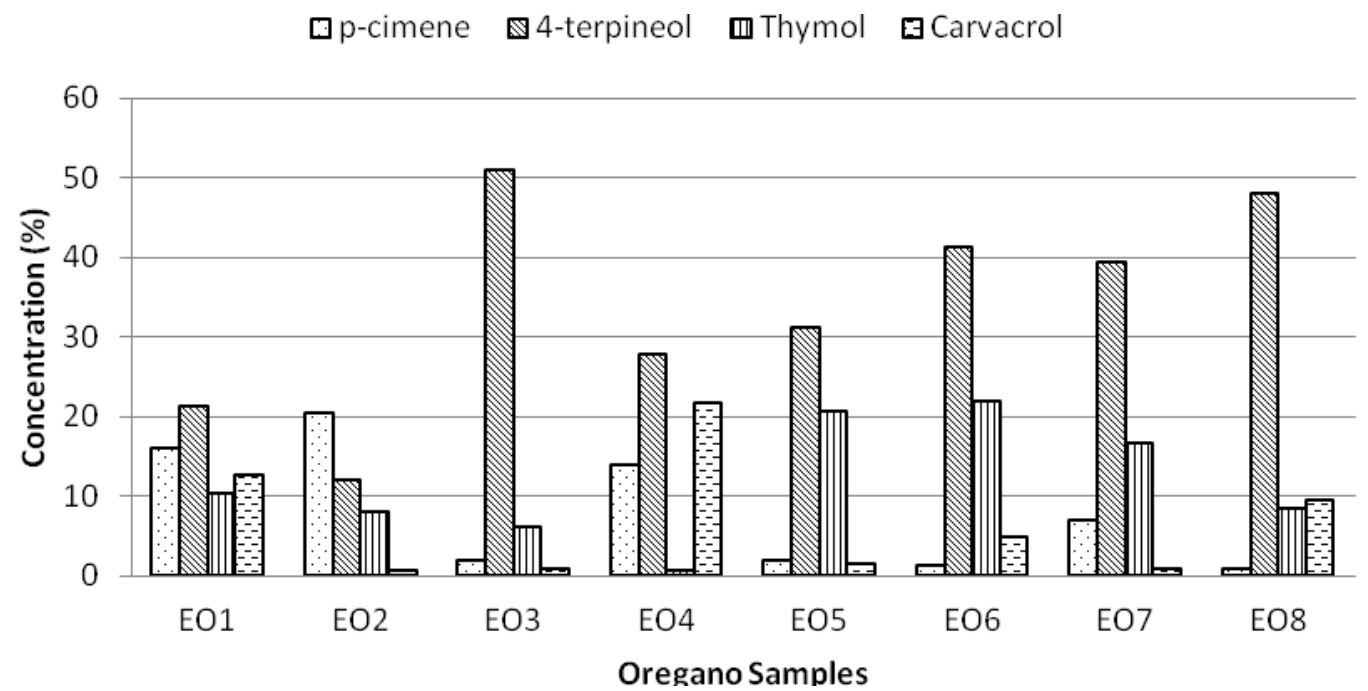

Figure 1. Graph of concentration (\%) of compounds p-cymene, 4-terpineol, thymol and carvacrol, in oregano oil samples. EO1, Erechim; EO2, Aves; EO3, El Moncayo; EO4, La Rosa; EO5, Del Gaúcho; EO 6, Goes; EO7, Treichel; EO8, Terranueva.

Table 2. Minimum Inhibitory concentration $\left(\mu \mathrm{LL}^{-1}\right)$ of the eight $O$. vulgare essential oils against Candida spp.

\begin{tabular}{lcccccccc}
\hline Isolate/essential oil & EO1 & EO2 & EO3 & EO4 & EO5 & EO6 & EO7 & EO8 \\
\hline C. albicans cutaneous canine & 2.5 & 5.0 & 10 & 10 & 5.0 & 2.5 & 5.0 & 2.5 \\
C. albicans mucous canine & 1.25 & 5.0 & 2.5 & 5.0 & 2.5 & 2.5 & 2.5 & 2.5 \\
C. albicans mucous canine & 2.5 & 2.5 & 10 & 5.0 & 2.5 & 5.0 & 2.5 & 2.5 \\
C. albicans mucous canine & 2.5 & 10 & 5.0 & 10 & 5.0 & 5.0 & 5.0 & 1.25 \\
C. albicans mucous canine & 2.5 & 10 & 5.0 & 5.0 & 2.5 & 2.5 & 10 & 2.5 \\
C. albicans ATCC 18804 & 0.65 & 2.5 & 2.5 & 2.5 & 5.0 & 2.5 & 1.2 & 1.25 \\
C. albicans ATCC 44858 & 1.25 & 2.5 & 5.0 & 5.0 & 2.5 & 2.5 & 2.5 & 2.5 \\
C. albicans ATCC 4053 & 1.25 & 10 & 5.0 & 10 & 2.5 & 5.0 & 2.5 & 2.5 \\
C. albicans IOC 3691 & 2.5 & 2.5 & 2.5 & 2.5 & 2.5 & 2.5 & 2.5 & 2.5 \\
C. parapsilosis ATCC 22019 & 1.25 & 2.5 & 5.0 & 5.0 & 2.5 & 2.5 & 2.5 & 2.5 \\
C. lusitanie ATCC 34449 & 1.25 & 5.0 & 2.5 & 1.2 & 1.2 & 5.0 & 2.5 & 1.25 \\
C. krusei ATCC 34135 & 2.5 & 2.5 & 5.0 & 5.0 & 10 & 2.5 & 2.5 & 2.5 \\
\hline
\end{tabular}

Table 3. $\mathrm{MIC}_{50}$ and $\mathrm{MIC}_{90}$ of eight oil extracts from O. vulgare against Candida spp isolates strains from regions of South Brazil and controls.

\begin{tabular}{|c|c|c|c|c|c|c|c|c|c|}
\hline \multirow{2}{*}{ EO } & \multicolumn{5}{|c|}{ Number (\%) of strains inhibited } & \multirow{2}{*}{$\mathrm{MIC}_{50}$} & \multirow{2}{*}{$\mathrm{MIC}_{90}$} & \multirow{2}{*}{ Thymol/Carvacrol } & \multirow{2}{*}{ Rate } \\
\hline & $0.62 \mu \mathrm{L} / \mathrm{mL}$ & $1.25 \mu \mathrm{L} / \mathrm{mL}$ & $2.5 \mu \mathrm{L} / \mathrm{mL}$ & $5 \mu \mathrm{L} / \mathrm{mL}$ & $10 \mu \mathrm{L} / \mathrm{mL}$ & & & & \\
\hline OE1 & $1(8.3)$ & $5(4.16)$ & $6(50)$ & 0 & 0 & 0.69 & 3.54 & $10.2 / 12.67$ & 0.80 \\
\hline OE2 & 0 & 0 & $6(50)$ & $3(25)$ & $3(25)$ & 0.6 & 6.83 & $7.88 / 0.5$ & 15.76 \\
\hline OE3 & 0 & 0 & $4(33.3)$ & $6(50)$ & $2(16.6)$ & 0.6 & 7.32 & $6.18 / 0.71$ & 8.7 \\
\hline OE4 & 0 & $1(8.3)$ & $2(16.6)$ & $6(50)$ & $3(25)$ & 0.6 & 8.01 & $0.58 / 21.58$ & 0.02 \\
\hline OE5 & 0 & $1(8.3)$ & $7(58.3)$ & $3(25)$ & $1(8.3)$ & 0.6 & 4.97 & $20.62 / 1.34$ & 15.38 \\
\hline OE6 & 0 & 0 & $8(66.6)$ & $4(33.3)$ & 0 & 0.68 & 5.07 & $21.95 / 4.71$ & 4.66 \\
\hline OE7 & 0 & $1(8.3)$ & $8(66.6)$ & $2(16.6)$ & $1(8.3)$ & 0.6 & 4.6 & $16.68 / 0.77$ & 21.66 \\
\hline OE8 & 0 & $3(25)$ & $9(75)$ & 0 & 0 & 0.6 & 3.87 & $8.42 / 9.44$ & 0.89 \\
\hline
\end{tabular}


example, in samples which showed lower $\mathrm{MIC}_{90}$ (EO1 and EO8), the rate of thymol/carvacrol was 0.80 and 0.89 , respectively, that is, very close concentrations [EO1, (10.20/12.67) and EO8 (8.42/9.44)].

Several authors believe that aromatic ring with a polar functional group, is responsible for antimicrobial activity (Milos et al., 2000; Lambert et al., 2001). It is suggested that the presence of this group and hydroxyl group $(-\mathrm{OH})$, would form hydrogen bond with the active microbial enzyme small sites. Therefore, it is possible to suppose that these groups (aromatic ring and hydroxyl group) are responsible for antimicrobial activity (Milos et al., 2000; Lambert et al., 2001; Ultee et al., 2002).

\section{Conclusion}

Results demonstrate that differences between concentrations of thymol and carvacrol influenced the $\mathrm{MIC}_{90}$ of $O$. vulgare oils against yeasts studied. Balance of concentration of phenolic compounds, thymol and carvacrol, seems to have synergic and positive effect on growth inhibition of different species of Candida, however the eight oils analyzed presented antifungal activity in vitro.

\section{ACKNOWLEDGEMENTS}

We are grateful to the Brazilian Foundations (CAPES, $\mathrm{CNPq}$ and FAPERGS) for the financial support and scholarship to M. B. Cleff.

\section{REFERENCES}

Arango ACM, Sánchez JGB, Galvis LAB (2004). Productos naturales con actividad antimicótica. Rev. Esp. Quimiot., 17:325-331.

Arcila-Lozano CC, Guadalupe LP, Salvador LU, Mejía EG (2004). El orégano: propiedades, composición y actividad biológica de sus componentes. ALAN. 54:1-24.

Busatta C, Mossi AJ, Rodrigues MRA, Cansian RL, Oliveira JV (2007). Evaluation of Origanum vulgare essential oil as antimicrobial agent in sausage. Braz. J. Microbiol. 38:610-616.

Busatta C, Vidal RS, Popiolski AS, Mossi AJ, Dariva C, Rodrigues MRA, Corazza FC, Corazza ML, Oliveira JV, Cansian RL (2008). Application of Origanum majorana L. essential oil as an antimicrobial agent in sausage. Food Microbiol. 25:207-211.

Chami N, Chami F, Bennis S, Trouillas J, Remma A (2004). Antifungal treatment with carvacrol and eugenol of oral candidiasis in immunosuppressd rats. Braz. J. Infect. Dis. 8:217-226.

Cleff MB, Meinerz ARM, Sallis ES, Antunes TA, Mattei A, Rodrigues MRA, Meireles MCA, Mello JRB (2008b). Toxicidade Pré-Clínica em doses repetidas do óleo essencial do Origanum Vulgare L. (Orégano) em ratas Wistar. Latin Am. J. Phar. 27:704-709.

Cleff MB, Meinerz ARM, Schuch LFD, Rodrigues MRA, Meireles MCA, Mello JRB (2008a). In vitro activity of the essential oil of Origanum vulgare against Sporothrix schenckii. Arq. Bras. Med. Vet. Zoot. 60:513-516.

Cleff MB, Silva GM, Meinerz ARM, Madrid IM, Martins AA, Fonseca AO, Nascente OS, Meireles MCA, Mello JRB (2007). Infecção cutânea em cão por Candida albicans. Rev. Vet. Zoot. 14(2):164-168.
Cleff MB, Meinerz, ARM, Xavier M, Schuch LFD, Meireles MCA, Rodrigues MRA, Mello JRB (2010). In vitro susceptibility of Origanum vulgare essential oil against Candida species. Braz. J. Microbiol. 41:116-123.

Cox SD, Mann CM, Markham JL, Bell HC, Gustafson JE, Warmington JR, Wyllie SG (2000). The mode of antimicrobial action of the essential oil of Melaleuca alternifolia (tea tree oil). J. Appl. Microb. 88:170-175.

Giordani R, Regli P, Kaloustian J, Mikaïl C, Abou L, Portugal H (2004). Antifungal effect of various essential oils against Candida albicans. Potentiation of antifungal action of Amphotericin B by essential oil from Thymus vulgaris. Phytot Res. 18(12):990-995.

Lambert RJW, Skandamis PN, Coote PJ, Nychas GJ (2001). A study of the minimum inhibitory concentration and mode of action of oregano esssencial oil, thymol and carvacrol. J. Appl Microb. 91:453-462.

Magill SS, Shields C, Sears CL, Choti M, Merz WG (2006). Triazole Cross-Resistance among Candida spp.: Case Report, Occurrence among bloodstream isolates, and implications for antifungal therapy. J. Clin. Microbiol. 44(2):529-535.

Milos M, Mastelic J, Jerkovic I (2000). Chemical composition and antioxidant effect of glycosidically bound volatile compounds from oregano (Origanum vulgare L. spp. hirtum). Food Chem. 71:79-83.

Moretti A, Posteraro B, Boncio L, Gaperis E, Agnetti F, Raspa M (2004). Diffuse cutaneous candidiasis in a dog. Diagnostic by PCR-REA. Rev. Iberoam. Micol. 21(3):139-142.

Mueller RS, Bettenay SV, Shipstone M (2002). Cutaneous candidiasis in a dog caused by Candida guilliermondii. Vet. Rec. 150(23):728730 .

Nostro A, Blanco AR, Cantelli MA, Enea V, Flamini G, Morelli I, Sudano RA, Alonzo V (2004). Susceptibility of methicillin-resistant staphylococci to oregano essential oil, carvacrol and thymol. FEMS Microb. Lett. 230(2):191-195.

Rehder VLG, Machado ALM, Delarmelina C, Sartoratto A, Figueira GM, Duarte MCT (2004). Composição química e atividade antimicrobiana do óleo essencial de Origanum applii e Origanum vulgare. Rev. Bras. PI. Med. 6(2):67-71.

Rodrigues MRA, Krause LC, Caramão EB, Santos JG, Dariva C, Oliveira JV (2004). Chemical composition and extraction yield of the extract of Origanum vulgare obtained from sub- and supercritical $\mathrm{CO}_{2}$. J. Agric. Food Chem. 52(10):3042-3047.

Santos Jr. ID, Souza IAM, Borges RG, Souza LB, Santana WJ, Coutinho HDM (2005). General traits of action, treatment and fungal resistance to fluconazol. Sci. Med. 15:189-197.

Sartoratto A, Machado ALM, Delarmelina C, Figueira GM, Dusrte MCT, Rehder VLG (2004). Composition and antimicrobial activity of essential oils from aromatic plants used in Brazil. Braz. J. Microb. 35:275-280.

Sikkema J, de Bont JA, Poolman B (1994). Interactons of cyclic hydrocarbons with biological membranes. J. Biol. Chem. 269(11):8022-8028.

Sikkema J, de Bont JA, Poolman B (1995). Mechanisms of membrane toxicity of hydrocarbons. Microbiol. Rev. 59(2):201-222.

Simões CMO, Schenkel EP, Gosmann G, Palazzo de Mello JC, Mentz LA, (2003). In: UFRGS (Ed). Farmacognosia: da planta ao medicamento. Porto Alegre, RS, Brazil. pp. 1102.

Ultee A, Bennik MHJ, Moezelaar R (2002). The phenolic hydroxyl group of carvacrol is essential for action against the food-borne pathogen Bacillus cereus. Appl. Environ. Microbiol. 68(2):1561-1568. 